Tokyo metropolitan areas. The data were provided by clinical psychiatrists who were blind to the study hypothesis. Hospital diagnosis was used. We defined the index year from August 1957, following the very first wave of the epidemic, to July 1958. We compared the number of schizophrenic births in each month of the index year with the average number of births in the corresponding month of the two years before, and following, the index year.

There were 147 schizophrenics born during the index year and 689 in the four control years. The distribution of birth rates in the index year $(1957 / 58)$ was compared with that of the average birth rates over the four control years. A $\chi^{2}$ test for comparison of distributions of schizophrenic births between these index and control groups yielded 10.50 on 11 d.f. (degrees of freedom), indicating an overall non-significant difference. However, when adjusted residuals (ARs) (Haberman, 1973) were examined, the observed number of births $(n=20)$ in April 1958, four months after the peak influenza deaths, was found to be unusually high $(A R s=2.253, P<0.012)$ compared with the average number of births $(n=12.50)$ over the four control years. Calculation of the ratios of affected births in each month of the index year to the average number of births in the corresponding month in the control years revealed that the risk of later developing schizophrenia was elevated by $60 \%$ in those exposed to the peak of the epidemic, four months before birth.

Although the present study is limited by the relatively small sample size, our results support the reports of O'Callaghan et al (1991) and Mednick et al (1988). Furthermore, the fact that the ratio of general population births in April 1958 to the average of population births in the four control years is 0.995 , suggests that the excess of schizophrenic births cannot be explained by a changing birth pattern in the general population. The period four months before birth corresponds roughly to the 5th-6th month of gestation. However, taking into account the time lag between the peak of prevalence of, and that of death rates from, influenza, the susceptible period appears to be between the 3rd and 6th month of gestation. This study is therefore compatible with the view that maternal exposure to influenza in the second trimester increases the risk of later schizophrenia in the foetus.

Barr, C. E., Mednick, S. A. \& Munk-Jorgensen, P. (1990) Exposure to influenza epidemics during gestation and adult schizophrenia: a 40-year study. Archives of General Psychiatry, 47, 869-874.

Crow, T. J., Done, D. J. \& Johnstone, E. C. (1992) Schizophrenia is not due to maternal influenza in the second (or other) trimester of pregnancy. Schizophrenia Research, 6, 99-100
Fahy, T. A., Jones, P. B., Sham, P. C., el al (1992) Schizophrenia in afro-Caribbeans in the UK following prenatal exposure to the 1957 A2 influenza epidemic. Schizophrenia Research, 6, 98-99.

Haberman, S. J. (1973) The analysis of residuals in cross-classified tables. Biometrics, 29, 205-220.

Kendell, R. E. \& KEMP, I. W. (1989) Maternal influenza in the etiology of schizophrenia. Archives of General Psychiatry. 46, 878-882.

Mednick, S. A., Machon, R. A., Huttenen, M. O., el al (1988) Adult schizophrenia following prenatal exposure to an influenza epidemic. Archives of General Psychiatry, 45, 189-192.

O' Callaghan, E., Sham, P. C., Takei, N., et al (1991) Schizophrenia after prenatal exposure to 1957 A2 influenza epidemic. Lancet, 337, 1248-1250.

Torrey, E. F., Bowler, A. E. \& RAwlings, R. (1992) Schizophrenia and the 1957 influenza epidemic. Schizophrenia Research. 6, 100

H. KUNUGI

S. NANKO

Department of Psychiatry

Teikyo University School of Medicine

Kaga

Itabashi-Ku

Tokyo 173

Genetics Department

Institute of Psychiatry

Denmark Hill

London SE5 8AF

Schizophrenia following prenatal exposure to influenza epidemics between 1939 and 1960

SIR: The correlation between maternal viral infection and the later occurrence of increased incidence of schizophrenia appears initially to be most convincing. The study of Sham et al (Journal, April 1992, 160, 461-466) uses influenza deaths to identify epidemics occurring at what are hypothesised to be vulnerable gestational periods of development.

Another hypothesis worthy of consideration is that children who are born during an influenza epidemic are more likely to have lost a grandparent in the pre- or post-natal period due to the influenza itself. In 1978, Walsh investigated the concurrence of grandparent death and the birth of an offspring who subsequently developed a schizophrenic illness. She found that of a sample of 70 schizophrenic patients, $41 \%$ experienced grandparental death within two years before or following a birth. In contrast, this concurrence of events was found in only $20 \%$ of families in a disturbed, non-schizophrenic group and in only $8 \%$ of cases in a normal control group.

The study is but one of several that suggest that, in mourning, a bereaved parent may be emotionally unavailable to spouse and infant at critical stages of development or that the process of mourning itself may be blocked and the child may assume a special 
role as an emotional substitute for this loss. The hypothesis may be spurious, but until it is explored and refuted casts a shadow of doubt on the conclusion that maternal viral infection is an important cause of schizophrenia.

WALSH, F. W. (1978) Concurrent grandparent death and birth of schizophrenic offspring: an intriguing finding. Family Process, 17, 457-463.

JOHN SPENCER

Sir Charles Gairdner Hospital

The Queen Elizabeth II Medical Centre

Verdun St

Nedlunds

Western Australia 6009

\section{Declining incidence of hysteria}

SIR: The declining incidence of hysteria in an Indian state (Nandi et al, Journal, January 1992, 160,87-91) is an interesting example of sociocultural changes influencing the expression of emotional distress. In a similar way, as modernisation and an emphasis on individual freedom have led to an increase in personal autonomy and introspection in the Western world, it has been speculated that the expression of emotional distress has moved from the bodily mode to the psychological mode, causing a dramatic reduction in the incidence of conversion disorders (Leff, 1988).

As a parallel phenomenon, deliberate self-harm has been increasing in the past few decades in the West. In India, it is unusual to find the syndrome of deliberate self-harm which involves repetitive episodes of low-lethality deliberate self-harm in nonpsychotic, non-mentally impaired individuals. This common, well-recognised and stable syndrome in the West shows several consistent similarities with hysteria, especially conversion reactions (Merskey, 1979). These include: (a) a preponderance of younger females, (b) a common direction towards an escape from an unbearable situation, (c) the occurrence of gain from resolution of a conflict, (d) dependency and regression in the personalities involved, (e) a strongly manipulative effect upon the environment leading to secondary gains and (f) association with sexual conflict. In addition, there is often $(\mathrm{g})$ a tendency to cluster in epidemics and $(h)$ the indifference of the wrist-slasher to the act of cutting closely resembles the "belle indifference" of the hysteric. Psychiatrists who have worked in both the developing world and the West are immediately struck by these similarities. The personal reaction of the treating doctor is identical in both cases with unconscious resentment at apparent deception, resulting in the labelling of such behaviour as 'immature' and 'silly'.
Patients who harm themselves often describe a state of dissociation during the act and an analgesia to the pain resulting from the act, both are appparently hysterical mechanisms. It is also interesting to note that eating disorders have been reported in association with both hysteria (Kay \& Leigh, 1954) and deliberate self-harm (Favazza et al, 1989). There is also some anecdotal evidence of a combination of dysorexia, female genital self-mutilation, and hysteria, described as Caenis syndrome (Goldney \& Simpson, 1975). Diagnostically most cases of manipulative, impulsive and low-lethality self-harm are now placed under the broad category of Borderline Personality Disorder. Merskey (1979) has argued for a special category of "Hysteriform Borderline Disorder" for cases where borderline ego defences of projective identification, massive denial and splitting are present along with conversion symptoms.

As a reaction against helplessness, both hysteria and deliberate self-harm are possibly similar "physical preverbal messages". The pathoplastic influence of cultural differences that determine these presentations are most likely to be in the autonomydependence and activity-passivity domains. It would be interesting to see if a parallel increase in the incidence of deliberate self-harm follows in India.

Favazza, A. R., Derosear, L. \& Conterio, K. (1989) Self mutilation and eating disorders. Suicide and Life-Threatening Behaviour, 19, 352-361.

GOLDNEY, R. D., \& Simpson, I. S. (1975) Female genital selfmutilation, dysorexia and the hysterical personality: the Caenis syndrome. Canadian Psychiatric Association Journal, 20, 435-441.

KAY, D. W. K. \& LEGH, A. D. (1954) The natural history, treatment and progress of anorexia nervosa based on a study of 38 patients. Journal of Mental Science, 100, 411-431.

LEF, J. (1988) Psychiatry Around the Globe. London: Gaskell. MerskeY, H. (1979) The Analysis of Hysteria. London: Ballière Tindall.

Swaran P. Singh

Alan S. LeE

Department of Psychiatry

University Hospital

Queen's Medical Centre

Nottingham NG7 2UH

\section{Anorexia nervosa and $\mathrm{XY}$ gonadal dysgenesis}

SiR: We recently reported (McCluskey \& Lacey, Journal, January 1992, 160, 114-116) a case of anorexia nervosa in a woman with $\mathrm{XY}$ gonadal dysgenesis: the anorexia stemming not only from the biological and psychological confusion inherent in the dysgenesis but also from its investigation and treatment.

Dr Lee (Journal, May 1992, 160, 713-714) makes an important diagnostic point about which we agree, 